\title{
Paradoxical effect of obesity on hemorrhagic transformation after acute ischemic stroke
}

\author{
Chi Kyung Kim ${ }^{1,2}$, Wi-Sun Ryu ${ }^{3}$, Beom Joon Kim ${ }^{4}$ and Seung-Hoon Lee ${ }^{1,2^{*}}$
}

\begin{abstract}
Background: Among the patients with established coronary artery diseases, obese patients tend to have a more favorable prognosis, which is called as obesity paradox. Interestingly, mildly obese patients who underwent coronary revascularization had a lower risk of bleeding. In this context, we have investigated the association between obesity and hemorrhagic transformation (HTf) after acute ischemic stroke.

Methods: A total of 365 patients with first-ever acute ischemic stroke were included in this study. Demographic, clinical and radiological information was collected and HTf was evaluated through follow-up T2*-weighted gradient-recalled echo MRI performed usually within 1 week after occurrence of stroke. Body mass index was calculated, and obesity was defined using the World Health Organization Western Pacific Regional Office criteria.

Results: The HTf was identified in 59 patients (16.2\%). As the severity of obesity increased, the occurrence of HTf decreased. Compared with the normal weight group and after controlling possible confounders including acute and previous treatment, stroke severity and subtype, the risk of HTf decreased significantly in the obese group (odds ratio, 0.39; 95\% confidence interval, 0.17-0.87).

Conclusions: The better outcome for HTf seen in obese patients suggests the existence of a "bleeding-obesity paradox" in acute ischemic stroke.
\end{abstract}

Keywords: Obesity, Hemorrhagic transformation, Bleeding-obesity paradox, Ischemic stroke, Body mass index

\section{Background}

Hemorrhagic transformation (HTf) frequently occurs after ischemic stroke with or without thrombolytic treatment $[1,2]$. It was known that HTf after acute ischemic stroke was associated with poor outcome and delayed the initiation of proper anticoagulation treatment for stroke with cardioembolism [3]. Although certain studies have demonstrated the association between old age [4], high systolic pressure [5], or thrombolytic treatment [6] with HTf, the predictive factor for HTf after acute ischemic stroke is still elusive.

Obesity affects more than a billion adults worldwide, and is implicated as one of the major risk factors of cardiovascular diseases $[7,8]$. However, in patients with established coronary artery diseases, obese patients tend

\footnotetext{
* Correspondence: sb0516@snu.ac.kr

'Department of Neurology, Seoul National University Hospital, 101 Daehak-ro, Jongno-gu, Seoul 110-744, Republic of Korea

${ }^{2}$ Clinical Research Center for Stroke, Biomedical Research Institute, Seoul

National University Hospital, Seoul, Republic of Korea

Full list of author information is available at the end of the article
}

to have a more favorable prognosis, which is called as obesity paradox $[8,9]$. Interestingly, according to a recent study, mild obese patients who underwent coronary revascularization had a lower incidence of periprocedural bleeding, and the authors in that study called this phenomenon as "bleeding-obesity paradox" [10].

In ischemic stroke, HTf occurs after extravasation of blood over damaged cerebral vascular endothelium and is more directly associated with disease itself than bleeding after coronary revascularization [11]. However, few studies have investigated the effects of obesity on the bleeding after ischemic stroke. In this context, we sought to investigate the association between obesity and HTf, and assessed whether "bleeding-obesity paradox" exists in acute ischemic stroke.

\section{Methods}

A total of 744 first-ever acute ischemic stroke patients who had been admitted to Seoul National University Hospital within 7 days from disease onset between October 2002

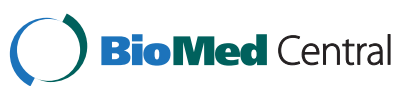


and March 2006 were consecutively enrolled in this study. According to the classification of Trial of Org 10172 in Acute Stroke Treatment, amongst the chosen patients, subjects with the following conditions were excluded from this study: transient ischemic attack $(n=79 ; \quad \mathrm{HTf}=0)$, strokes attributable to small vessel disease $(n=221 ; \mathrm{HTf}=0)$, or strokes of other determined etiology $(n=9 ; \mathrm{HTf}=1)$ [12]. Patients without complete workups ( $\mathrm{n}=70$; 10 without initial MRI, 37 without follow-up MRI, 14 without checking height, and 9 without laboratory workups) were further excluded. The excluded 70 patients had more severe stroke than included patients, and in-hospital death rate of excluded patients was higher than that of included patients. However, other demographic and cardiovascular risk factors including the average and the distribution of body mass index (BMI) were not different between two groups (Additional file 1: Table S1). Therefore, our study population consisted of a total of 365 patients with firstever acute ischemic stroke. The patient or the patient's next of kin was provided informed consent, and the study was approved by the institutional review board at Seoul National University Hospital (H-0911-065-301).

Baseline demographic and clinical information collected at admission included age at onset, gender, body weight and height at the time of admission, hypertension (a high systolic blood pressure was defined as at least $140 \mathrm{mmHg}$ at discharge, and a diastolic blood pressure as at least $90 \mathrm{mmHg}$ at discharge. Hypertension was defined as a high systolic blood pressure or a high diastolic blood pressure or as the current use of antihypertensive medication), diabetes (previous use of antidiabetic medication, fasting blood glucose $>7.0 \mathrm{mmol} / \mathrm{L}$ ), hyperlipidemia (previous use of lipid-lowering medication, total cholesterol $>6.0 \mathrm{mmol} / \mathrm{L}$ at admission), smoking, previous use of antiplatelet or anticoagulant medications, systolic and diastolic blood pressure levels at admission, the level of blood glucose and total cholesterol at admission, the initial National Institute of Health Stroke Scale (NIHSS) score, and thrombolytic or/and acute heparin treatment during acute stage. BMI was calculated as weight (in kilograms) divided by height (in meters squared), an obesity was defined using the criteria of the World Health Organization (WHO) Western Pacific Regional Office, which reflects a different risk factors and body fat distribution in the Asian Population [13].

All the participants underwent initial brain MRI before the initiation of thrombolytic or antithrombotic therapy (within 24 hours after admission) and follow-up brain T2\%-weighted gradient-recalled echo (GRE) MRI usually within 1 week after occurrence of stroke (follow-up days: mean $\pm \mathrm{SD}, 6.7 \pm 1.4$ ). The MRI studies were performed using 1.5-Tesla superconducting magnet (GE Healthcare, Chalfont St. Giles, UK). The standardized MRI protocol consisted of axial T2-weighted spin echo (repetition time/echo time, 2500 to $4500 / 80$ to $112 \mathrm{~ms}$; flip angle, $20^{\circ}$; slice thickness, $5 \mathrm{~mm}$; gap width, $2 \mathrm{~mm}$ ) and diffusion-weighted imaging (repetition time/echo time, 4000/73 ms; flip angle, $90^{\circ}$; slice thickness, $5 \mathrm{~mm}$; gap width, $2 \mathrm{~mm}$ ). The GRE images were obtained in the axial plane with the following parameters: repetition time/echo time, 500/15 ms; flip angle, 26; matrix size, $256 \times 192$; slice thickness, $6 \mathrm{~mm}$; and gap width, $2 \mathrm{~mm}$. The HTf was identified when follow-up GRE images showed a low-signal area consistent with blood within the acute ischemic lesion, according to the pre-specified criteria [14]. White matter lesions (WMLs) were judged as being absent, or present as punctuate, early confluent or confluent abnormalities as seen on T2-weighted MR images, according to the previously proposed method [15]. Early confluent or confluent lesions were designated as advanced WMLs in this study. Microbleeds were defined as focal homogenous areas with a diameter of 2 to $5 \mathrm{~mm}$ as previously described $[16,17]$.

The $x^{2}$ test and the Student $t$ test were used to compare categorical data and continuous data of the subjects, respectively. The distribution of demographic, clinical, and radiological variables were analyzed using $X^{2}$ test for trends in proportion. The odds ratio (OR) and 95\% confidence interval (CI) for the HTf in each obesity status were calculated using binary logic regression analyses. For multivariable analyses, potential confounders were adjusted such as age, gender, hypertension, diabetes, hyperlipidemia, current smoking, initial NIHSS, thrombolysis, acute heparin treatment, previous use of antiplatelet or anticoagulant, stroke subtype, and the presence of advanced WMLs and microbleeds. The adjusted OR and 95\% CI for the HTf or cerebral microbleeds were calculated by multivariable analysis. Probability values were 2 -tailed, and $\mathrm{P}$ values $<0.05$ were considered significant. All statistical analyses were performed using SPSS 19.0 (SPSS Inc., Chicago, IL).

\section{Results}

Among 365 subjects, there were 246 men and 119 women. Subjects' age ranged from 16 to 95 years, and their mean age was 64.7 years. Average BMI of subjects was $24.1 \mathrm{~kg} / \mathrm{m}^{2}$. According to the WHO obesity criteria for the Asian-Pacific Population, 94 patients (25.8\%) were classified as overweight (BMI, 23.0-24.9 kg/m²) and 146 (40\%) were classified as obese (BMI, $\geq 25.0 \mathrm{~kg} / \mathrm{m}^{2}$ ).

The HTf was noted in 59 patients $(16.2 \%)$. Table 1 shows that BMI was significantly lower in subjects with $\operatorname{HTf}\left(23.1 \mathrm{~kg} / \mathrm{m}^{2}\right)$ that in those without HTf $\left(24.2 \mathrm{~kg} / \mathrm{m}^{2}\right)$. The average of initial NIHSS score and the proportions with cardioembolism and thrombolytic treatment were greater in subjects with HTf. However, the average age, glucose level, cholesterol level, and systolic and diastolic blood pressure at admission, and the proportions of 
Table 1 Baseline characteristics of patients with/without hemorrhagic transformation

\begin{tabular}{|c|c|c|c|}
\hline & \multicolumn{2}{|c|}{ Hemorrhagic transformation } & \multirow[t]{2}{*}{$P$ value } \\
\hline & Absent $(n=306)$ & Present $(n=59)$ & \\
\hline \multicolumn{4}{|l|}{ Demographic } \\
\hline Age, y & $64.4 \pm 12.4$ & $66.3 \pm 9.1$ & 0.28 \\
\hline Gender, male & $209(68.3 \%)$ & $37(62.7 \%)$ & 0.45 \\
\hline Body-mass index, $\mathrm{kg} / \mathrm{m}^{2}+$ & $24.2 \pm 3.2$ & $23.1 \pm 4.2$ & 0.02 \\
\hline \multicolumn{4}{|l|}{ Clinical } \\
\hline Hypertension & $182(59.3 \%)$ & $37(62.7 \%)$ & 0.67 \\
\hline Diabetes & $93(30.4 \%)$ & $17(28.8 \%)$ & 0.88 \\
\hline Hyperlipidemia & $47(15.4 \%)$ & $5(8.5 \%)$ & 0.22 \\
\hline Smoking & & & 0.95 \\
\hline Never & $192(62.7 \%)$ & $37(62.7 \%)$ & \\
\hline Past & $51(16.7 \%)$ & $9(15.3 \%)$ & \\
\hline Current & $63(20.6 \%)$ & $13(22 \%)$ & \\
\hline Previous use of antiplatelet agents & $9(2.9 \%)$ & $2(3.4 \%)$ & 0.69 \\
\hline Previous use of anticoagulation & $9(2.9 \%)$ & $2(3.4 \%)$ & 0.69 \\
\hline Initial NIHSS score, median (IQR)† & $8(4-16)$ & $3(2-6)$ & $<0.01$ \\
\hline \multicolumn{4}{|l|}{ Acute treatment } \\
\hline Thrombolysist & $10(3.3 \%)$ & $14(23.7 \%)$ & $<0.01$ \\
\hline Acute heparin treatment & $98(32 \%)$ & $21(35.6 \%)$ & 0.65 \\
\hline Stroke subtype & & & $<0.01$ \\
\hline Large artery atherosclerosis & $135(44.1 \%)$ & $11(18.6 \%)$ & \\
\hline Cardioembolism & $81(26.5 \%)$ & $30(50.8 \%)$ & \\
\hline Undetermined & $90(29.4 \%)$ & $18(30.5 \%)$ & \\
\hline \multicolumn{4}{|l|}{ Laboratory } \\
\hline Glucose, mmol/L & $6.5 \pm 2.1$ & $6.9 \pm 2.3$ & 0.14 \\
\hline Total cholesterol, mmol/L & $4.6 \pm 1.0$ & $4.6 \pm 1.0$ & 0.64 \\
\hline Systolic blood pressure, $\mathrm{mmHg}$ & $152 \pm 25$ & $153 \pm 27$ & 0.87 \\
\hline Diastolic blood pressure, $\mathrm{mmHg}$ & $88 \pm 15$ & $90 \pm 17$ & 0.39 \\
\hline Prolonged PT/aPTT (\%) & $36(11.8 \%)$ & $8(13.6 \%)$ & 0.66 \\
\hline \multicolumn{4}{|l|}{ Radiological } \\
\hline Advanced WMLs & $76(25.2 \%)$ & $16(28.1 \%)$ & 0.63 \\
\hline Presence of microbleeds & $68(22.7 \%)$ & $15(26.3 \%)$ & 0.61 \\
\hline
\end{tabular}

Values are mean $\pm S D$ or number of participants (percentage).

NIHSS indicates National Institute of Health Stroke Scale; WMLs, white matter lesion; and IQR, Interquartile range.

${ }^{*} P$ values were obtained using the $X^{2}$ test for categorical data, and the Student $t$ test for continuous data.

$+P<0.05$.

gender, hypertension, diabetes, hyperlipidemia, smoking, previous use of antiplatelet agents and anticoagulation, acute heparin treatment, and the presence of advanced WMLs and microbleeds were not different between those with and without HTf. As the severity of obesity increased, the incidence of HTf decreased, and the average of initial NIHSS score also decreased (Table 2). The proportion of subjects with hypertension increased according to the severity of obesity.
In the obese group, $15(10.3 \%)$ subjects had HTf, and compared with the normal weight group, the crude OR for HTf in the obese group was 0.36 (95\% CI, 0.18 to 0.71). After adjusting age, gender, hypertension, diabetes, hyperlipidemia, atrial fibrillation (reflecting stroke subtype), smoking, initial NIHSS score (reflecting stroke severity), thrombolytic and acute heparin treatment, and the presence of advanced WMLs and microbleeds, a $61 \%$ risk reduction of HTf in the obese group existed when 
Table 2 The proportions of clinical radiological variables by the severity of obesity

\begin{tabular}{|c|c|c|c|c|c|c|}
\hline Variables $(n=365)$ & $\begin{array}{l}\text { Underweight } \\
\left(<18.5 \mathrm{~kg} / \mathrm{m}^{2}\right) \\
\mathrm{n}=18(4.9 \%)\end{array}$ & $\begin{array}{c}\text { Normal weight } \\
\left(18.5-22.9 \mathrm{~kg} / \mathrm{m}^{2}\right) \\
\mathrm{n}=107(29.3 \%)\end{array}$ & $\begin{array}{c}\text { Overweight } \\
\left(23.0-24.9 \mathrm{~kg} / \mathrm{m}^{2}\right) \\
\mathrm{n}=94(25.8 \%)\end{array}$ & $\begin{array}{c}\text { Obesity I } \\
\left(25.0-29.9 \mathrm{~kg} / \mathrm{m}^{2}\right) \\
\mathrm{n}=134(36.7 \%)\end{array}$ & $\begin{array}{c}\text { Obesity II } \\
\left(\geq 30 \mathrm{~kg} / \mathrm{m}^{2}\right) \\
\mathrm{n}=12(3.3 \%)\end{array}$ & $P$ for trend ${ }^{*}$ \\
\hline \multicolumn{7}{|l|}{ Demographic } \\
\hline Age, y & $71.1 \pm 11.2$ & $65.3 \pm 12.7$ & $65.2 \pm 11.8$ & $63.4 \pm 11.1$ & $61.0 \pm 12.8$ & 0.08 \\
\hline Gender, male & $15(83.3 \%)$ & $73(68.2 \%)$ & $62(66.0 \%)$ & $88(65.7 \%)$ & $8(66.7 \%)$ & 0.67 \\
\hline \multicolumn{7}{|l|}{ Clinical } \\
\hline Hypertensiont & 7 (38.9\%) & $50(46.7 \%)$ & $58(61.7 \%)$ & $96(71.6 \%)$ & $8(66.7 \%)$ & $<0.01$ \\
\hline Diabetes & $3(16.7 \%)$ & $29(27.1 \%)$ & $32(34.0 \%)$ & $44(32.8 \%)$ & $2(16.7 \%)$ & 0.38 \\
\hline Hyperlipidemia & $1(5.6 \%)$ & $13(12.1 \%)$ & $17(18.1 \%)$ & $20(14.9 \%)$ & $1(8.3 \%)$ & 0.55 \\
\hline Current smoking & 7 (38.9\%) & $21(19.6 \%)$ & $23(24.5 \%)$ & $23(17.2 \%)$ & $2(16.7 \%)$ & 0.23 \\
\hline Initial NIHSS scoret & $5(3-12)$ & $5(2-11)$ & $4(2-9)$ & $3(2-5)$ & $3(1-6)$ & $<0.01$ \\
\hline Thrombolysis & $0(0 \%)$ & $9(8.4 \%)$ & $6(6.4 \%)$ & $9(6.7 \%)$ & $0(0 \%)$ & 0.61 \\
\hline Acute heparin treatment & $9(50 \%)$ & 37 (34.6\%) & $31(33 \%)$ & $39(29.1 \%)$ & $3(25 \%)$ & 0.44 \\
\hline Antiplatelet Use & 0 & $5(4.7 \%)$ & $4(4.3 \%)$ & $2(1.5 \%)$ & 0 & 0.48 \\
\hline Warfarin Use & 0 & $2(1.9 \%)$ & $5(5.3 \%)$ & $4(3.0 \%)$ & 0 & 0.54 \\
\hline \multicolumn{7}{|l|}{ Radiological } \\
\hline Hemorrhagic transformationt & $4(22.2 \%)$ & $26(24.3 \%)$ & $14(14.9 \%)$ & $14(10.4 \%)$ & $1(8.3 \%)$ & 0.04 \\
\hline Advanced WMLs & $6(35.3 \%)$ & $26(25 \%)$ & $24(26.1 \%)$ & $35(26.3 \%)$ & $1(8.3 \%)$ & 0.6 \\
\hline Presence of microbleeds & $2(11.8 \%)$ & $20(19.4 \%)$ & $21(22.8 \%)$ & $36(27.1 \%)$ & $4(33.3 \%)$ & 0.42 \\
\hline
\end{tabular}

Values are mean $\pm S D$, median (interquartile range), or number of participants (percentage).

NIHSS indicates National Institute of Health Stroke Scale; WMLs, white matter lesion.

*Based on $X^{2}$ test of trend across the severity of obesity.

$+P<0.05$.

compared with the normal weight group (Table 3). However, ORs for HTf or cerebral microbleeds did not decrease in the overweight or the obese groups compared with the normal group (Table 4).

\section{Discussion and Conclusions}

In the present study on patients with first-ever acute ischemic stroke, we found that the occurrence of HTf decreased according to the severity of obesity. In particular,

Table 3 The risk of hemorrhagic transformation according to the severity of obesity

\begin{tabular}{lcc}
\hline & \multicolumn{2}{c}{ OR for HTf } \\
\cline { 2 - 3 } & $\begin{array}{c}\text { Unadjusted } \\
\text { OR } \mathbf{( 9 5 \% ~ C l )}\end{array}$ & $\begin{array}{c}\text { Adjusted } \\
\text { OR }(\mathbf{9 5 \%} \mathbf{C l})\end{array}$ \\
\hline Underweight $\left(<18.5 \mathrm{~kg} / \mathrm{m}^{2}\right)$ & $0.89(0.27-2.94)$ & $1.05(0.28-3.96)$ \\
Normal $\left(18.5-22.9 \mathrm{~kg} / \mathrm{m}^{2}\right)$ & $1.00($ reference) & 1.00 (reference) \\
Overweight $\left(23.0-24.9 \mathrm{~kg} / \mathrm{m}^{2}\right)$ & $0.55(0.27-1.12)$ & $0.48(0.21-1.11)$ \\
Obesity $\left(\geq 25 \mathrm{~kg} / \mathrm{m}^{2}\right)$ & $0.36(0.18-0.71) \dagger$ & $0.39(0.17-0.87) \dagger$ \\
\hline
\end{tabular}

$\mathrm{HTf}$ indicated hemorrhagic transformation; $\mathrm{OR}$, odds ratio; and $\mathrm{Cl}$, confidence interval.

*ORs $(95 \% \mathrm{Cl})$ were adjusted by age, gender, hypertension, diabetes, hyperlipidemia, current smoking, initial NIHSS score, thrombolysis, acute heparin treatment, stroke subtype, previous aspirin use, previous warfarin use, and the presence of advanced WMLs and cerebral microbleeds. $+P<0.05$. obese subjects had a significantly decreased risk of HTf when compared with the normal weight group, after adjusting possible confounders including acute and previous treatment, and stroke severity and subtype.

Although our finding may seem controversial, the results are not surprising. Considering HTf as poor prognostic factor [3], the paradoxical effect of obesity on death after ischemic stroke, the most deleterious outcome, has been reported. In a Danish cohort of hospitalized acute stroke

Table 4 The risk of hemorrhagic transformation or cerebral microbleeds according to the severity of obesity

\begin{tabular}{lcc}
\hline & \multicolumn{2}{c}{ OR for HTf or cerebral microbleeds } \\
\cline { 2 - 3 } & $\begin{array}{c}\text { Unadjusted } \\
\text { OR }(\mathbf{9 5 \%} \mathbf{C I})\end{array}$ & $\begin{array}{c}\text { Adjusted } \\
\text { OR }(\mathbf{9 5 \%} \mathbf{C I}) *\end{array}$ \\
\hline Underweight $\left(<18.5 \mathrm{~kg} / \mathrm{m}^{2}\right)$ & $0.71(0.23-2.18)$ & $0.65(0.19-2.25)$ \\
Normal $\left(18.5-22.9 \mathrm{~kg} / \mathrm{m}^{2}\right)$ & 1.00 (reference) & 1.00 (reference) \\
Overweight $\left(23.0-24.9 \mathrm{~kg} / \mathrm{m}^{2}\right)$ & $0.87(0.48-1.57)$ & $0.80(0.42-1.52)$ \\
Obesity $\left(\geq 25 \mathrm{~kg} / \mathrm{m}^{2}\right)$ & $0.93(0.55-1.57)$ & $0.92(0.51-1.69)$
\end{tabular}

HTf indicated hemorrhagic transformation; OR, odds ratio; and $\mathrm{Cl}$, confidence interval.

${ }^{*}$ ORs $(95 \% \mathrm{Cl})$ were adjusted by age, gender, hypertension, diabetes,

hyperlipemia, current smoking, initial NIHSS score, thrombolysis, acute heparin treatment, stroke subtype, previous aspirin use, previous warfarin use, and the presence of advanced WMLs. 
patients, post-stroke mortality was inversely related to obesity [18]. The phenomenon was also noted in an analysis of a health and nutrition status survey in US individuals, which showed that in aged population, obese stroke survivors tend to have a lower risk of mortality than patients with a normal weight [19]. However, the mechanism, which states that obesity increases the longevity in obese patient after ischemic stroke is not clear. Based on our findings and a review of the previous studies, HTf might be related to "obesity paradox" in acute ischemic stroke.

In the present study it was observed that as increasing of obesity severity, the proportion of cardioembolic stroke and severe stroke (reflected by initial NIHSS score) decreased, despite of the elevated prevalence of hypertension [20]. The incidence of HTf may be influenced by the differences in these baseline characteristics among BMI groups [10]. To reduce these confounding effects, we conducted a multivariable analysis after adjusting various possible confounders including the nature of stroke (severity and subtype), acute and previous treatment. After this adjustment, the presence of obesity independently predicted the occurrence of HTf in our study. However, the association between microbleeds and obesity was not elucidated in this study with first-ever acute ischemic stroke patients. Although microbleeds were suggested as a risk factor for cerebral hemorrhage [21], they are not a confirmed mediator of hemorrhagic transformation after ischemic stroke. Compared with HTf, the weak relationship between obesity and microbleeds may reflect the different pathophysiology of HTf and cerebral microbleeds. While the abrupt reperfusion after ischemic tissues elicits HTf, the spontaneous rupture of injured small arterioles in brain leads cerebral microbleeds.

For the cause of bleeding-obesity paradox, biological explanations exist. First, alterations in circulating coagulation factors have been suggested. Obesity has been related to higher levels of multiple coagulation factors such as factor VII, VIII, fibrinogen, and plasminogen activator inhibitor-1 [22,23]. Second, in studies investigating the association between BMI and platelet aggregation, patients with $\mathrm{BMI} \geq 25 \mathrm{~kg} / \mathrm{m}^{2}$ were found to have suboptimal response to antithrombotics than patients of normal weight $[24,25]$. However, this phenomenon was evaluated in normal or coronary artery disease subjects, and not in acute stroke patients. To clearly explain the "bleeding-obesity paradox," the assessment of the coagulability and drug response in obese patient with acute ischemic stroke is required.

In the present investigation, a number of points require further clarification. First, due to the limitation of study population, we focused on the relatively mild obese patients and did not evaluate the phenomenon of "bleeding-obesity paradox" in severely obese patients. To assess the effect of BMI as a whole from underweight to severe obese, we suggest that future studies on ischemic stroke patients with widely-spread BMI should be undertaken. Second, the long-term outcome of HTf, which is a major poor prognostic factor in acute ischemic stroke, was not evaluated in this study. Thus, we could not assess "obesity paradox" per se in this study. Third, more severe stroke patients were excluded because they could not undergo brain MRI or did not have clinical information such as height, and the effects of obesity on HTf in severe stroke patients might not be evaluated completely.

The present study is unique because it documents the better results about HTf in obese patients with acute ischemic stroke, which persists after adjustment for acute treatment and stroke severity and subtype. Thus, we suggest the existence of a "bleeding-obesity paradox" in ischemic stroke, and propose that the inverse association between HTf and obesity in ischemic stroke may be considered in the management of acute stroke patients.

\section{Additional file}

Additional file 1: Table S1. Baseline characteristics of excluded patients.

\section{Competing interests}

The authors declare that they have no competing interests.

\section{Authors' contributions}

CKK and S-HL devised the original study concept and design. BJK and W-SR participated in the acquisition of data. CKK and S-HL performed statistical analyses, interpreted the results and wrote the manuscript. All authors read and approved the final manuscript.

\section{Acknowledgements}

This work was supported by grants of the Korean Health Technology R\&D Project, Ministry of Health and Welfare, Republic of Korea (A111014). The analyses and interpretations of the data and the final content of the article were produced independently of the financial sponsors.

\section{Author details}

${ }^{1}$ Department of Neurology, Seoul National University Hospital, 101 Daehak-ro, Jongno-gu, Seoul 110-744, Republic of Korea. ${ }^{2}$ Clinical Research Center for Stroke, Biomedical Research Institute, Seoul National University Hospital, Seoul, Republic of Korea. ${ }^{3}$ Department of Neurology, Dongguk University Ilsan Hospital, Goyang, Republic of Korea. ${ }^{4}$ Department of Neurology, Seoul National University Bundang Hospital, Seongnam, Republic of Korea.

Received: 29 October 2012 Accepted: 18 September 2013 Published: 23 September 2013

\section{References}

1. Okada Y, Yamaguchi T, Minematsu K, Miyashita T, Sawada T, Sadoshima S, Fujishima M, Omae T: Hemorrhagic transformation in cerebral embolism. Stroke 1989, 20:598-603.

2. Larrue V, von Kummer RR, Muller A, Bluhmki E: Risk factors for severe hemorrhagic transformation in ischemic stroke patients treated with recombinant tissue plasminogen activator: a secondary analysis of the European-Australasian Acute Stroke Study (ECASS II). Stroke 2001, 32:438-441.

3. Dzialowski I, Pexman JH, Barber PA, Demchuk AM, Buchan AM, Hill MD: Asymptomatic hemorrhage after thrombolysis may not be benign: prognosis by hemorrhage type in the Canadian alteplase for stroke effectiveness study registry. Stroke 2007, 38:75-79.

4. Hacke W, Donnan G, Fieschi C, Kaste M, von Kummer R, Broderick JP, Brott T, Frankel M, Grotta JC, Haley EC Jr, et al: Association of outcome with 
early stroke treatment: pooled analysis of ATLANTIS, ECASS, and NINDS rt-PA stroke trials. Lancet 2004, 363:768-774.

5. Castellanos M, Leira R, Serena J, Pumar JM, Lizasoain I, Castillo J, Davalos A: Plasma metalloproteinase-9 concentration predicts hemorrhagic transformation in acute ischemic stroke. Stroke 2003, 34:40-46.

6. Larrue V, von Kummer R, del Zoppo G, Bluhmki E: Hemorrhagic transformation in acute ischemic stroke. Potential contributing factors in the European Cooperative Acute Stroke Study. Stroke 1997, 28:957-960.

7. Haslam DW, James WP: Obesity. Lancet 2005, 366:1197-1209.

8. Lavie CJ, Milani RV, Ventura HO: Obesity and cardiovascular disease: risk factor, paradox, and impact of weight loss. J Am Coll Cardiol 2009, 53:1925-1932.

9. Romero-Corral A, Montori VM, Somers VK, Korinek J, Thomas RJ, Allison TG, Mookadam F, Lopez-Jimenez F: Association of bodyweight with total mortality and with cardiovascular events in coronary artery disease: a systematic review of cohort studies. Lancet 2006, 368:666-678.

10. Delhaye C, Wakabayashi K, Maluenda G, Belle L, Ben-Dor I, Gonzalez MA, Gaglia MA Jr, Torguson R, Xue Z, Suddath WO, et al: Body mass index and bleeding complications after percutaneous coronary intervention: does bivalirudin make a difference? Am Heart J 2010, 159:1139-1146.

11. Wang $X$, Lo EH: Triggers and mediators of hemorrhagic transformation in cerebral ischemia. Mol Neurobiol 2003, 28:229-244.

12. Adams HP Jr, Bendixen BH, Kappelle LJ, Biller J, Love BB, Gordon DL, Marsh EE: Classification of subtype of acute ischemic stroke. Definitions for use in a multicenter clinical trial. TOAST. Trial of Org 10172 in Acute Stroke Treatment. Stroke 1993, 24:35-41.

13. World Health Organization International Obesity Task Force: International Association for the Study of Obesity, the Asia-Pacific Perspective: Redefining Obesity and its Treatment. Sydney: Health Communications; 2000.

14. Hacke W, Kaste M, Fieschi C, Toni D, Lesaffre E, von Kummer R, Boysen G, Bluhmki E, Hoxter G, Mahagne MH, et al: Intravenous thrombolysis with recombinant tissue plasminogen activator for acute hemispheric stroke. The European Cooperative Acute Stroke Study (ECASS). JAMA 1995, 274:1017-1025.

15. Fazekas F, Niederkorn K, Schmidt R, Offenbacher H, Horner S, Bertha G, Lechner $\mathrm{H}$ : White matter signal abnormalities in normal individuals: correlation with carotid ultrasonography, cerebral blood flow measurements, and cerebrovascular risk factors. Stroke 1988, 19:1285-1288.

16. Lee SH, Kwon SJ, Kim KS, Yoon BW, Roh JK: Cerebral microbleeds in patients with hypertensive stroke. Topographical distribution in the supratentorial area. J Neurol 2004, 251:1183-1189.

17. Biffi A, Greenberg SM: Cerebral amyloid angiopathy: a systematic review. J Clin Neurol 2011, 7:1-9.

18. Olsen TS, Dehlendorff C, Petersen HG, Andersen KK: Body mass index and poststroke mortality. Neuroepidemiology 2008, 30:93-100.

19. Towfighi A, Ovbiagele B: The impact of body mass index on mortality after stroke. Stroke 2009, 40:2704-2708.

20. Zhao D, Wang W, Liu J, Cheng J, Liu J, Qin LP: Association between body mass index and ten-year-accumulative-risk of hypertension. Zhonghua Liu Xing Bing Xue Za Zhi 2009, 30:435-438.

21. Lim JS, Kwon HM: Risk of silent stroke in patients older than 60 years: risk assessment and clinical perspectives. Clin Interv Aging 2010, 5:239-251.

22. Reiner AP, Siscovick DS, Rosendaal FR: Hemostatic risk factors and arterial thrombotic disease. Thromb Haemost 2001, 85:584-595.

23. Cushman M, Yanez D, Psaty BM, Fried LP, Heiss G, Lee M, Polak JF, Savage PJ, Tracy RP: Association of fibrinogen and coagulation factors VII and VIII with cardiovascular risk factors in the elderly: the cardiovascular health study. Cardiovascular health study investigators. Am J Epidemiol 1996, 143:665-676.

24. Cuisset T, Frere C, Quilici J, Morange PE, Camoin L, Bali L, Lambert M, Juhan-Vague I, Alessi MC, Bonnet JL: Relationship between aspirin and clopidogrel responses in acute coronary syndrome and clinical predictors of non response. Thromb Res 2009, 123:597-603.

25. Sibbing D, von Beckerath O, Schomig A, Kastrati A, von Beckerath N: Impact of body mass index on platelet aggregation after administration of a high loading dose of $600 \mathrm{mg}$ of clopidogrel before percutaneous coronary intervention. Am J Cardiol 2007, 100:203-205.

\section{doi:10.1186/1471-2377-13-123}

Cite this article as: Kim et al.: Paradoxical effect of obesity on hemorrhagic transformation after acute ischemic stroke. BMC Neurology 2013 13:123.

\section{Submit your next manuscript to BioMed Central and take full advantage of:}

- Convenient online submission

- Thorough peer review

- No space constraints or color figure charges

- Immediate publication on acceptance

- Inclusion in PubMed, CAS, Scopus and Google Scholar

- Research which is freely available for redistribution 